\title{
The Sustainability Issue; What Meaning for the Economic and Human Activity?
}

\author{
Giovanni Antonio COSSIGA ${ }^{1}$ \\ ${ }^{1}$ Presidente Collegio sindaci Policlinico Umberto I, Università Sapienza - ROMA, Italy \\ Correspondence: Giovanni Antonio COSSIGA, Presidente Collegio sindaci Policlinico Umberto I, Università Sapienza \\ - ROMA, Italy.
}

Received: February 10, 2020

Accepted: March 3, 2020

Available online: March 18, 2020

doi:10.11114/aef.v7i3.4773

URL: https://doi.org/10.11114/aef.v7i3.4773

\begin{abstract}
The sustainability issue, understood as a good relationship between humankind and nature, can offer the opportunity to analyze certain aspects of the economic theory. If we admit that the stability in economy is a natural condition for linear growth and instead the conjuncture is a trouble for growth due to the loss of natural balance, some consequences will follow. The long fight against instability has not been won, always struggling between inflation and deflation. It follows that the fight against inflation first and then deflation couldn't counter the real malaise of the global economy: the instability. That is the deviation of economic systems from the natural path of balance with nature. Therefore, the results obtained struggling with monetary alterations, although significant, would be temporary and unable to solve the core of the matter. It follows that the economic support policies have essentially addressed the formal aspect, I would say just indicative of the imbalance, without obtaining stable results in the natural balance recovery. From this point of view, the interventions of fiscal policy, despite some good tests obtained by trying to reduce the strength of the 2008-2010 financial crisis, have not solved however the poisonous aftermath of deflation. Moreover, during the last decade, the health of global economic systems has always required, to be maintained, a defense in the form of supporting policies through neo-Keynesian interventions. And not only that. Because the monetary policy used all its weapons, even unconventional ones, to defeat deflation: nonetheless, it didn't achieve anything but just a mitigation of phenomena. Always provided, anyway, that the wave of new liquidity continues, as requested by the markets. The point is therefore which is the exit strategy from this situation, considering that the progressive exhaustion of the resources of fiscal and monetary policies sets the expectation of a potential progressive recession on a global basis. Well, according to the sustainability theory the recession is not a bad thing in itself, but it's rather a cure whose impact we must learn to measure, having the view to mitigate the most negative social effects.
\end{abstract}

Keywords: economy of sustainability, sub-world of instability, monetary messengers, conjuncture as remedies

\section{Introduction}

The sustainability issue is not limited to the context of relations within the economic field, but obviously it covers the vast domain of sociality and relationships between humanity and nature. By the way, to define the economic science exclusively from the mere economic relations point of view could mean to be limited only to the formal effects of cyclical policies. In other words, the scenario of human activity would be reduced to a brief period, while is concealed or omitted a long-term vision, which is the cornerstone in the relationship between humanity and nature.

According to this point of view, we can understand that the overall evolution of humankind is not an adventure in the unknown and indeterminate future. Otherwise we couldn't understand the human journey through the history and the undeniable ability to overcome the unimaginable adversities endured by the past generations. Above all, with the aim to entrust the future generations with an acceptable living condition on earth.

The difficulty in envisaging the inalienable relationship between humanity and nature lies perhaps in the natural reaction times that are in no way comparable with those of our life but look towards a generational horizon. This difference between the times according to mankind and the times according to nature, however, can disclose an imperative to which the life should answer. That is, the living conditions on earth shouldn't be deeply altered by the human presence but should remain somewhat unchanged over time.

The condition is therefore that each generation should leave to the next one the heritage of natural resources sufficiently 
unaltered, so that life can continue over time. Looking at the long term, we can observe that the instruments that from long time now are usual of political actions can take on a different meaning and interest, if not temporary or even accessory. Because in general the short-term interventions, which are typical of fiscal and also monetary policy, can give some results, even excellent and substantial, but usually they have a short life and often a poisonous aftermath.

The problem lies in the recurrence of phenomena, which are reproducing because in the short period perspective they can be partially or entirely paused but essentially remain unresolved and hidden within the folds of economic systems. So, far from solutions we have only postponements or, even worse, further alterations occurring after a more or less short time. Very short, indeed, if considered in the light of times of the nature's world. As saying that we have a brief appeasement rather than a solution. Just enough to allow the economic management to boast (temporary) benefits to the community.

A vision linked to the idea that the community is enslaved because unable to have a common will (at least in its majority), which is coherent in economic and social terms. Therefore, it must be guided by trusted leaders and experts. This concept is at least unjustified. If we admit this improper assumption, then it should be said that democracies are an aberration and just a sort of public show.

Now it's clear that the common path of humankind cannot be ascribed only to some enlightened men along the history (how many?), but it can only be explained by accepting that the great passages are the result of the work made by communities with their common expectations and hopes. Even in our current age where we can see a great oscillation of collectivity preferences in the selection of leaders, we must admit that there is a widespread dissatisfaction creating and suddenly destroying them in a somewhat disturbing way. As saying that the formulas and recipes prescribed by the political classes within the democratic area are no longer in tune with the deep aspirations of peoples.

How to give therefore some logical interpretation to this growing dynamism of popular will, if we do not realize that there must be an irrevocable relationship between the economy's natural process and the expression of the popular will. We can also argue that the community is a sort of terminal on which the incentives for an acceptable relationship between humanity and nature are charged, in the form of aspirations and hopes.

This is just to say that the problem is not only the leadership and the ways of conducting the economy. The real problem lies in the social tension towards coherence between popular will and leadership's aspirations and programs. Inside this coherence there is the real possibility to realize the objective of stability on the economic route, consistent with the evolution of nature. The discrepancy between the social and economic project of the masses and projects and programs of the leadership, is a prodrome of instability for the economy and the society. Therefore, it's also signs of a widespread disaffection with leadership and consequently with the singular dynamics observed within the executive managers of political society.

Based on this approach, which links the behavior of the masses and the economic and social development - stable and coherent - with the natural tendencies, the community is the privileged channel for the relationship between humanity and nature. Therefore, the stable and sustainable balance of human activities in the social and economic field essentially realizes the task of preserving resources for future generations and achieves also the relative consistency between the natural (slow) evolution and the development of human societies.

The breakdown of this balance, instead, has repercussions in the anomalies of economic and social growth and in the progressive disenchantment of the community towards the political classes, although selected with the popular vote but with a weak agreement with their programs. (Cossiga,2019)

\subsection{The Sustainability Follows the (Long) Times of Natural Evolution}

We can believe that there is a potential contradiction between the sustainability of human behavior on the planet and the economic situation that follows the times of human life and individual daily actions. A contradiction that could explain perhaps the discrepancy between individual thought, passions and expectations and those proper to a community. The individual passions and expectations travel in fact throughout the daily life, while the community lives an unavoidable relationship with the nature that welcomes the life and reflects the long evolution wave according to material laws and their rhythms.

How to interpret now the excited and premonitory panic of the great crack of October '29. "The market was in the grip of a blind implacable fear. He was, in truth, panicked. A sinister shout could be heard outside the Exchange. There was a crowd ... More people gathered around waiting, although obviously no one knew what to do. On the roof of one of the tallest buildings appeared a worker, who had to make repairs, and immediately the crowd assumed that it was a suicide 
and began to wait impatiently for it to fall down. Small groups of people were formed around the offices of stock exchange commissioners throughout the city, across the country ... " 1

We can interpret the behavior of the community only if we admit that the collectivity has a voice and an inspiration other than the individuals. Therefore, its inspiration must be found in hints and sensations directly deriving from the market or rather from the economy, as interpreter of the permeating tension towards stability. Twenty million Americans at the time bought shares, in the wake of the strange rule that only $10 \%$ of the cost was to be paid immediately, except to request a loan on the shares and so continuing the joke. A perverse mechanism certainly, not unlike the one that would allow ninety years later to grant mortgages to those who were unable to pay the installments; notwithstanding, he could make later the request to increase the loan on the precarious claim of the increased value of the house not yet paid!

Also, the anomaly of the new liquidity creation that starts the hyper-speculative process cannot be explained in the light of a rational market. Yet it has occurred; not only that, because it has been repeated despite the experience gained and the great experts that analyzed those events. How to explain the irrationality that was accumulated at that time? It is possible only if we admit that the phenomena of the unstable world are part of a mechanism with a coherent purpose. According to this approach, the irrational speculation would be an extreme remedy to restore the economy, which has become very unstable and distant from the equitable relationship between mankind and nature.

In other words, like the explosive rupture of the speculative bubble there is the clash between the naivety of individuals who believe in the possibility of unlimited growth and the strong intuition, instead, of the community that the irrational process has reached its end. But we could say also that the hyper-speculative exuberance is nothing else and nothing more than the multiplied behavior of individuals, selfishly attracted by the siren of an endless growth. Inevitably, therefore, the development of hyper-speculation and the start of the egoistic attraction towards endless growth is meaningless, unless connected to the final drama that finally sees the action of the community that puts an end to the unnatural economic massacre.

If it all makes sense, then it's inevitable that, under the sustainability sign, the dramatic events of ninety years ago and their repetition in the 2000 first decade are essentially a very strong, perhaps even catastrophic, signal of the breakdown of the relationship between humanity and nature. A very strong signal because the breakdown of the natural relationship has lasted so long over time that no other possibility was envisaged to bring the economy back to the balance's reason, because it was lost the way of the good relationship between mankind and nature.

Therefore, the problem would lie in the choice of the horizon where to project the decisions and the programs. In the sense that if we move our attention towards political activities only directed to daily events or to the conjuncture's troubles or to specific social tensions, we cannot expect solutions, but just buffers. The danger is that being limited to a temporary perspective, could prevail a survival hope for the leadership moving in contrast with the irrevocable tendency to the economic and social systems' stability. A choice that postpones solutions over time and, above all, undermines the trustful relationship between governments (with related programs) and the community. Because the expectations of the community, at least in the medium-long term, are shaped according to the guidelines dictated by the stability rule of economic and social systems.

The contrast between leadership and community can be read inside the alternating and rapid dynamics of programs and policies; a dynamic expressing a poor relevance of the programs proposed by the government coalitions regarding the highly important goals of the communities. This discrepancy is even wider when the projects and economic and social management programs are paralyzed when addressing the issue of the economic instability and the following social troubles.

In the search for solutions, therefore, the question seems to move around the search and identification of leaders able to read and to guess the real popular expectations, so avoiding to follow the route of small daily interventions, which essentially leave the situations unchanged. In a far-sighted expectation, a system becomes or could become unstable if diverted from the natural path of a good relationship between humanity and nature. The symptoms of this malaise are found in the dissolution of the growth potential, which instead is constant and linear in stable systems. The linearity of the economic growth is therefore transformed into the irregularity of the economic conjuncture and then into the fall of the systems' efficiency, so reducing the potential of the stability world.

An economy following the conjuncture sinuous rhythm is unstable. If the permanence in the instability sub-world continues over time, the irregularities can affect the social level for the tension created in the income distribution with its potential convergence on privileged categories, to the detriment of popular classes. As saying that the growing income gap within the society is a symptom of the growing instability inside the economy as well as of declining

\footnotetext{
${ }^{1}$ The Great Crash - John Kenneth Galbraith
} 
productivity and efficiency.

Responding to these eventualities with measures to alleviate the social malaise is essentially just a way to maintain the status quo and thus to allow a further divergence in income distribution. The adoption of measures increasing the tax burden for people with high incomes and great wealth could result as a simple panacea. And this because the levers of real power are in the hands of the great wealth holders and therefore seems somehow complicated any intervention of social justice, which would be certainly unacceptable for them. Moreover, the legal defense power of these categories is high and therefore the risk of a long postponement of the implementation time is quite real.

The perspective according to which the potential results are envisageable, is essential. In the short-term perspective, it could appear essential to make interventions to protect negative situations through ad hoc measures. In the long-term perspective, these temporary measures do not help but allow instead to maintain the status quo of social gap trouble.

\subsection{The Intervention of Support Policies in the Economic Management. The Risk of a Lower Efficiency}

The fiscal policy can be interpreted as a tool to "pause" an unstable economic system. An unstable system is subject to convulsions of the conjuncture, which is a typical instrument of the unstable world. With this instrument basically we introduce in the mechanism of potential growth the alternation of recessions, which in the absence of interventions tend to become more frequent due to the time spent in unstable conditions.

The recession is the weapon used by the natural correction system to restore, though paying a toll, the stability natural state of the altered system. The natural condition guarantees a constant and linear growth of the economy that rewards those economic systems that move observing sustainability and compatibility in the use of natural resources. This would mean that if we decide not to follow the stability natural path and, therefore, to oppose the recession consequence, we should expect as an unavoidable result that the economic system will remain in the unstable state.

Therefore, the actions of fiscal policy supporting the cycle would appear contradictory, although they could boast some appreciable results under certain conditions, such as the resumption of the economic cycle and the mitigated social tensions. Can this behavior mean that we are able to interfere with the natural correction mechanism of unstable systems and at the same time to guarantee an adjustment of instability? This hypothesis, that the tools of the economy at the fiscal level would be able to bring back to stability the cycle sinuosity, is linked to the idea that the economic reality is the unstable world of the economic cycle and recurring recessions.

Nevertheless, this hypothesis cannot explain those periods during which the economy grows in a linear and constant way for extended periods of time. Moreover, it doesn't provide any justification for the cycle behavior and above all for the onset of recessions. The recession is a penalty: why is it given? Obviously, is there a penalty to pay and why?

An event so serious and decisive for the economy and the whole society may not have been wanted by the Greek gods! Also, because usually the recession is linked with monetary events - such as inflation or deflation - which likewise do not have an apparent guide and follow a methodology that is a 'nobody's child'. Furthermore, if we let the economic cycle act without intervention, we can see that the phenomenon is out of sync. Indeed, the recessive wave, which is quite pronounced in the initial phase, changes and alters if the unstable condition continues to deteriorate. Thus, the recession that at the beginning is short after a long increasing phase, then becomes longer and deeper until to erase completely the resumption phase. At the same time, the monetary alterations (inflation or deflation) are worsening.

We are then facing a complex orchestration, without any direction, repetitive and aimed, as we have said, at recovering the stability of the altered system. Now, to believe that we can be able to manipulate this complex mechanism, aimed at reducing the incidence of corrective recession, seems quite difficult. Even more unlikely is to believe that we can in this way transform the growth, sinuous for our responsibility, into a linear and constant growth model. (Cossiga, 2017)

Therefore, facing the however undoubted results, obtained by the support policies in certain circumstances, we can try to interpret what effects the manipulation of the natural correction process may produce. However, one fact seems incontrovertible. That is, the fiscal policies to control the conjuncture cycle cannot have any substantial effect on the instability state, for the simple reason that the problem of instability is due to the attempt to subvert the rules of sustainable growth. Then the problem lies in protecting the life on the planet. And this isn't certainly the concern of the leaderships, who try to maintain the consensus through the balancing act of an apparently acceptable growth.

Therefore, essentially the cycle support policies are diluting the recession over time, in the sense that the growth supported by anti-cyclical policies tends to become creeping. Thus, it's true that the recession is somehow mitigated or postponed, but the economic growth fades and tends to follow the fate of deflationary prices: in fact, the prices move at an average of $0.5-1.5 \%$, that is below the base value close to $2 \%$ adopted by the Central Banks as the standard value of a good performance.

Currently, even the hypothesis of an inflation close to $2 \%$, as a base value of a good economic performance, seems impossible. Because the base value close to $2 \%$ is an abstract and hypothetical value that can occur if the economy 
tends to stability, that is if it grows in a constant and linear way. In other words, if we reach the stage of sustainability in the relationship between life and environment, an ideal and unrealized stage, only at that point the prices would tend to move around the ideal value close to $2 \%$. A value therefore only theorized and unverifiable indeed, which we can include among the great universal constants of the physical world. (Cossiga, 2018)

From this point of view, therefore, the possible advantages experienced with fiscal policies adopted to counteract a sharp decline in economy, should be uncertain and temporary. In other words, it's possible to confine within certain limits the free expression of corrective economic cycle, but we cannot reduce the instability condition. The corrective system is therefore paused, although the economic growth slows down and fades away.

The experience also shows that the economy suffering for creeping growth doesn't seem to have certain consequences on the instability correction. In fact, the signs of a potential improvement should show an attenuation of the deflation trend experienced during these years. Monetary signals, such as deflation, are obvious symptoms of the disease. A sort of monetary fever that, without any apparent guide, in an irrevocable way while the unstable condition lasts, is sharing with the community the information about the economic program diverging from the sustainability objective. And not only that. The measurement scale of deflation suffered by the various economies, is measuring the financial fragility index of each country or continental area. So, the inflation is very low for the most fragile countries which mark a significant decrease of the economic and social growth.

Thus, it sounds as a confirmation of the permanence of systems within the unstable condition with the economic systems suffering for deflation, despite the potential improvements recorded in terms of economic resilience through fiscal support programs. As shown in Figure 1, the deflation phenomenon diffusion is global, and its trend appears increasing over time; this is corresponding to a contemporary flat trend of the economic growth. Therefore, the effectiveness of fiscal policies in cycle support is undermined, because the expectations of a return to sustainable growth are at least temporarily disregarded.

Even in the United States, the decision to force the economic cycle with a powerful injection since 2018 and for three years of public resources in deficit, with the tax cutting to the advantage of privileged categories, did not show a decisive progress in the inflation rate. This inflation rate went beyond the two points in 2018, then dropped to 1.7 on average in 2019 and is now going towards 1.5\%, thus aligning with the European average. To make a whatever assumption about a next eventual recession in the USA and Europe is just an illusion.

Because the pressure exerted by fiscal and monetary policies, although now unfit to the struggle, will continue to remove as far as possible the feared specter of the recession, in the hope to see finally defeated the tension troubling the economy. But it's an illusion, no longer linked to solid economic reasons but to the aspiration of political elites, who are betting on the economic joke to maintain consensus and power.

Moreover, the stability of the economy as a guarantee for the current governments is now showing some flaws. Because the monetary signal that confirms the economy's suffering certainly clearly appears to the community. The community, in fact, should be considered as a real terminal of the relationship between humanity and nature. Very sensitive, therefore, to the evaluation of the signals about economy state, which certainly look at essential data, such as the economic cycle strength and the use of labor forces.

But the community is also carefully checking the suffering symptoms within the economic structure, despite the hiding coverage of fiscal and monetary policies. Also, because in the choice of the leaderships called to govern, the community does not limit its judgment only to the past but is projecting also, and perhaps mainly, that judgment to the future. A future described through sensations and impressions about the economy state, received by the community explicitly and implicitly from the economic system, as an instrument to be used on the relationship between humanity and nature. 


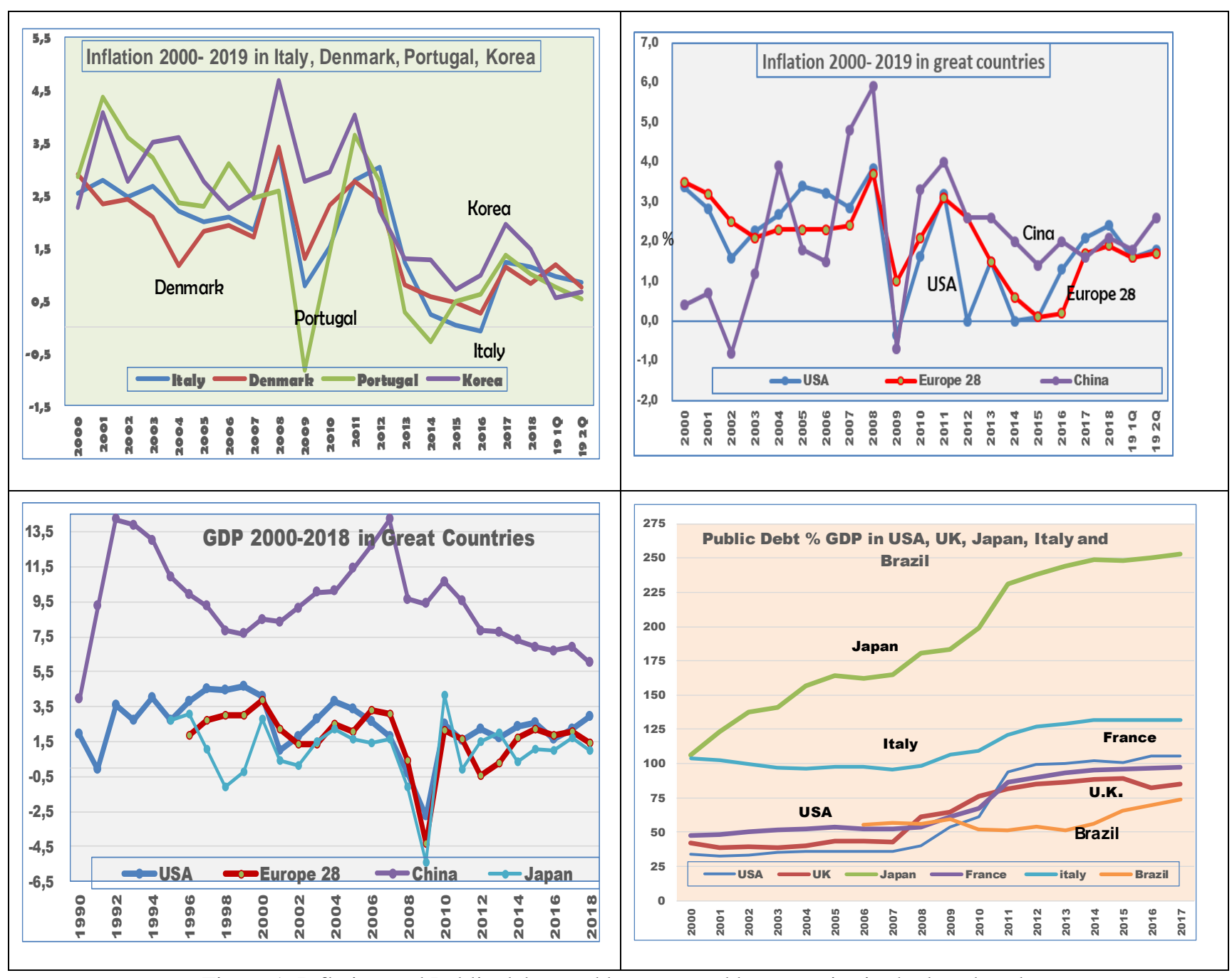

Figure 1. Inflation and Public debt trend by areas and by countries in the last decade

Source: Elaborations on OECD data

\subsection{Where Is Going the Global Economy after a Decade of Apparent Calm and Restrained Growth}

Complying with the experience, we can state that the long struggle, with inflation before and deflation now, didn't correct the global state of the economy, which continues to remain inside the instability sub-world in search of the lost coherence in sustainability. Hence, the long struggle with massive doses of fiscal interventions and unconventional monetary policies is basically causing a progressive degradation of the efficiency throughout the economic systems. Which have not been actually affected in the last decade by a true corrective recession, but at the same time these economic systems are losing points in terms of low or declining growth.

There is now the status quo problem: would the persistence in this midstream, which excludes the recession but suffers the penalization of economic growth, have in any case the merit of reducing and limiting the instability state, even in the absence of the periodic corrective recession? The answer may not seem positive. Because if the instability of the global economic system would show positive signs and glimmers for a return to the natural stability, we should have some clear signals. Which unfortunately are not so evident.

It isn't so much worrying the low and slightly falling inflation, because the signal is partially distorted by the strength of the policies supporting the cycle: these policies seem to have a mitigating effect on the decline of nominal prices and to support the economic growth, which is however increasingly weak. A double effect that can lead to inappropriate assessments about the alleged validity of monetary and fiscal policy.

Therefore, it's necessary to purify the inflation data from the effect due to the intervention of support policies. Since this is difficult to calculate, the fact remains that the boost effect on prices and economy through fiscal and monetary policies tends to be contracted over time. A widespread feeling within the market that looks with concern at the reduced 
impact on the prospects of economic support interventions, especially in the monetary policy field.

The problem to be solved is what effects or consequences could have an intervention policy, which removes the recession danger but with a possible price to be paid. Because the message coming from the economy is not reassuring at all. In the sense that it isn't proven that a low profile in the economic cycle over an extended period can have a somewhat equivalence to the missed recession. In other words, the penalized growth suffered by the economy to avoid a natural correction, could be worth at least to reduce instability and, therefore, to play as a weak alternative to the corrective function?

The answer can be equivocal, because it doesn't seem logical to exclude that a long pause in growth could basically correspond more or less to a similar decline produced by the corrective recession. To be able over time to mitigate the instability degree and to bring over time the economic system back on the sustainability path. If this were true, then we should expect a further long period of uncertainty in the economic growth and a consequent price weakness. A condition that resembles the current global economy, indeed.

On the other hand, this prospect of extended weak growth and low inflation seems to be accepted also by the main Central Banks. The European Central Bank, in the final meeting of the mandate of President Mario Draghi, confirmed the ultra-accommodative long-term policy and decided to resume from November 2019 the purchase of government and private securities. ${ }^{2}$ Likewise, also the US Federal Reserve under the presidency of Jerome H. Powell, made cuts on the reference rates for the third time in $2019^{3}$ and decided to proceed with the purchase of government and corporate securities to mitigate the pressure over the interbank market.

The monetary policy has now changed its style and has been transformed from a player controlling the market over the long term into an instrument to make direct interventions on the market.

The assumption that the long action of policies can somehow attenuate, at least partially, the tension due to the systems' instability, seems weaker when the support interventions become almost overbearing. In the sense that the presumption that we are able to interfere with the economic development process through further massive interventions can maybe mislead us. In this hypothesis, in fact, the latent correction entrusted to the creeping economic growth would be excluded, with a renewed block to the natural correction.

\footnotetext{
${ }^{2}$ At today's meeting the Governing Council of the European Central Bank (ECB) decided that the interest rate on the main refinancing operations and the interest rates on the marginal lending facility and the deposit facility will remain unchanged at $0.00 \%, 0.25 \%$ and $-0.50 \%$ respectively. The Governing Council expects the key ECB interest rates to remain at their present or lower levels until it has seen the inflation outlook robustly converge to a level sufficiently close to, but below, $2 \%$ within its projection horizon, and such convergence has been consistently reflected in underlying inflation dynamics.

As decided at the last Governing Council meeting in September, net purchases will be restarted under the Governing Council's asset purchase program (APP) at a monthly pace of $€ 20$ billion as from 1 November. The Governing Council expects them to run for as long as necessary to reinforce the accommodative impact of its policy rates, and to end shortly before it starts raising the key ECB interest rates. ECB Monetary policy decisions, 24 October 2019

${ }^{3}$ Consistent with its statutory mandate, the Committee seeks to foster maximum employment and price stability. In light of the implications of global developments for the economic outlook as well as muted inflation pressures, the Committee decided to lower the target range for the federal funds rate to 1-1/2 to 1-3/4 percent. This action supports the Committee's view that sustained expansion of economic activity, strong labor market conditions, and inflation near the Committee's symmetric 2 percent objective are the most likely outcomes, but uncertainties about this outlook remain. The Committee will continue to monitor the implications of incoming information for the economic outlook as it assesses the appropriate path of the target range for the federal funds rate.

In determining the timing and size of future adjustments to the target range for the federal funds rate, the Committee will assess realized and expected economic conditions relative to its maximum employment objective and its symmetric 2 percent inflation objective. Federal Reserve issues FOMC statement, October 30/2019

${ }^{4}$ Beyond providing updates on how the rate outlook is shaping up, the Fed could provide additional details on its asset-buying plans. The Central bank announced this month that it would begin buying Treasury bills, expanding its balance sheet holdings for the first time since the aftermath of the financial crisis. The move is an effort to ensure that the banking system has ample reserves - currency deposits at the Central bank - which keeps market plumbing working smoothly. It came after an obscure but important set of money market interest rates temporarily spiked in September. NYT - A Preview of the Fed Meeting, October 30/2019
} 
At this point we could think that the acceleration that the economic cycle undergoes due to the boost given by a strong fiscal intervention, would slow down quickly, so that we could expect a significant fall in the conjuncture, which in one or two-year period could reach $0.5-1 \%$ of annual growth. Actually, a limited blast disappearing early enough to bring the conjuncture cycle back to a very low or even zero level. So, the acceleration caused would have no other effect than to further postpone the long journey of economy into the tunnel of inconsistent growth.

The US case seems quite appropriate to describe a situation like the one mentioned above. The US economy in fact reacted to the impulse given by the tax reform, adopted in 2017 and entered into force in 2018.

The tax reform essentially cuts taxation to the benefit mostly of higher incomes, together with a large package of structural interventions. The economy, that was already traveling at around 2\% per year, gained below 3\% in 2018 and $2.3 \%$ in 2019. In the next two years, however, the upward pressure coming from the fiscal impulse should gradually decrease up to $1 \%$ on average. The strong contribution of public spending has given an accelerated dynamic to deficit and public debt: in the coming years, according to the CBO Analysis, the US deficit should exceed 100\% of GDP and beyond.

The US situation, like also the Euro-European context, shows a progressive exhaustion of the fiscal policy potential, due to the excessive deficit and public debt. The result is a significant shift of market pressure on the monetary policy, which is called to compensate in the weak cycle support. In the US case, moreover, remains monitored the potential effect of the derogation from the natural correction principle, imposed with a strong economic policy action, which acts in contrast.

For now, the market shows a slow decline in growth potential and the general sentiment is the expectation of a recession in the next 12 months. This prospect would be linked to the over ten years duration of the recovery after the 2008-2010 crisis, according to the thesis of a conjuncture regularly alternating resumptions and recessions. Unacceptable thesis, however, both because denied by experience and because the cyclical alternation rather than an economy's constant, is an economy's irregularity. Irregularity that occurs punctually when the economic systems escape from the growth linear motion, due to a serious breakdown regarding the environment sustainability.

The tension towards recession that the market feels, would be nothing but the symptom of natural correction, which anyway fails to perform its function due to the barrier placed by fiscal and monetary policies. Now, it seems that this obstacle to the corrective recession can progressively lose its strength, in presence of the public deficit widening (Figure 1) and the exhaustion of the potential of unconventional monetary policy measures.

An exhaustion degree that is more evident in Europe, both because the major states, except Germany, have used the potential of fiscal policy, and because of the size reached by the European Central Bank budget. The stock of Euro-system APP bonds stood at $€ 2,648$ billion at the end of September 2019. A condition that seems able to explain the prospect of a quite near economic situation downturn, already in progress in Europe, differently from the scenario of US economy.

\subsection{The Possible Perspective if the Potential for Fiscal Policy Intervention is Exhausted}

On the other hand, the possibility of an undefined and uncertain intervention made by support policies is unrealistic. Therefore, it seems somewhat convincing the idea that the feared economic recession can reappear once again, without any possibility that other tools could delay that natural event. The problem that arises now is whether, after years of blocked evolution of the natural correction, we would witness a contained or very intense recessive event. Apart from the negative cycle strength, which could certainly be different from the 2000s' financial crisis and therefore moderate, the concern remains strong about the possible global character of the probable next economic reversal.

The possibility that the event progressively would involve the global economy makes the expected scenario more worrying. At present, however, the coincidence of the process could be avoided, thus reducing the extent of potential social and economic damage. Let's not forget that the factors that actually blocked the way for the emergence of the natural correction are today less efficient and even non-operational, due to the abuse of economic support interventions during the past years. Even from this point of view, however, the global economy picture is uneven due to the different potential of economic systems - in the past and in the future - regarding the implementation of conjuncture protection tools.

Precisely for this reason, in fact, the potential reserve of public intervention even in deficit, within the various countries and continents is quite uneven, so the situation of world economies is not marked by a synchronous economic situation but by a patchy framework. With the US economy which still appears healthy, while the Euro-zone seems to be in trouble. So, apart from the just aired perspective of a progressive global recession, the fact remains that the specter of a close recession is affecting only some continental areas, with the exception meanwhile of North America and partially of Asia. 
Well, since the strong tendency to deflation emerged in the 2000s does not seem to be overcome by fiscal and monetary policies working together, the fact remains that the therapy used according to the classical scheme is unable to restore the sustainability condition inside the economy. Therefore, insisting on this kind of actions may not give the expected results. The test offered by the US economy can be important, because the maximum extension was given to the activity range of fiscal policy. Now, the anomaly in the behavior of the FED, which raised key rates three times in the second half of 2019 in a healty economy, opens questions about the prospects. ${ }^{5}$ Are these operations aimed to soften the economy's landing on a lower growth platform, at the European level?

If this hypothesis results possible and the engine of the North American economy may turn off, let say in the next two years, well, the probable result would be a further extension at a global level of the tendency to deflation. As saying that, after a decade of action against the low inflation, the condition of the global economy would be back to the starting point. Indeed, with a more marked presence urbi et orbi of the monetary threat, which is nothing more than an economic system message to signal to the communities that the economy has diverged from the stability track.

We are therefore at a turning point, after which we will have to admit that the intervention policy to support the conjuncture has become powerless or almost, to be able to fight a long instability affair. A condition of instability that wasn't overcome even after the severe and difficult period of the 2008-2010 financial crisis. Indeed, we should wonder whether the massive use of fiscal and monetary policies since the end of the last decade could be in some way responsible for the restriction faced today by the global economy. (Krugman, 2008)

In these circumstances, the prospect of a controlled recession in Europe shouldn't appear so worrying. Because, if the global economy context is discreetly strong, the potential damages of discontinuous recessions, that is not involving the global economy, can partially be controlled and contained. However, the problem remains that the economic cycle reversal is produced by a further widening of the income distribution at the expense of the most vulnerable categories. It is therefore essential to have the possibility to propose policies able to correct the distorted income distribution and to have a reserve of public intervention in order to contain the social troubles.

\section{Some Tests from the Economy of Sustainability Point of View}

\subsection{Towards the Exhaustion of Fiscal Policies. The Case of Italy}

The consensus mechanism that guarantees the political elites, therefore, seems to be a sort of "Penelope's shroud" that for decades has set the economy's management on this assumption: if the economy is somewhat going, the leaderships can withstand the varying popular moods. All recent events don't seem to justify this thesis. In the democratic West, we are witnessing a convulsive succession of political teams with not so many ideas other than to continue with the never-ending faith in the intervention power over the economy. This presumption appears even more surprising if we consider that in the most fragile countries from a financial point of view, a government is replaced within a year or so.

The case of Italy applies as a wide-range example. After the great oil shock of the seventies and the counter-shock of the eighties and then of the nineties, about sixteen governments succeeded each other to manage the economy. All of them with the purpose of giving new stimulus to the economy, which isn't brilliant now but anyway has been stagnant during the past twenty years.

All those governments with the same problem of a public debt over $120 \%$ of GDP already in 2000 and this situation apparently was demanding, despite the excessive indebtedness, to set fire to the growth ashes with the starter of Keynesian policies. Without result, of course. Nonetheless, that joke is still going on. It's quite clear now that in recent years there has been a progressive disagreement distance between the programs offered by the political forces and the community. Which appears increasingly unsatisfied about the poor successive political programs, unable to restore the stalled economy.

Well, the pretension that consensus can be achieved only by putting an offer of deficit fiscal policy on the plate is without consistency. Because the community has quite different expectations regarding the government of the economy. And is hopeless the attempt to mitigate the social imbalances with deficit measures in favor of the weakest categories. In the sense that the instability condition, which involves weak growth and low inflation, brings in its core the aberration of the income distribution in favor of the privileged categories. Moreover, the inequality in the wealth

\footnotetext{
${ }^{5}$ Since September 2019, the Fed has started a stimulus program trough repo contracts, after a mini-crisis that made short-term rates jump to $10 \%$. At the end of October, the overnight repo daily auctions, from the previous 75 billion, were raised to 120 billion dollars; moreover, the term repo auctions were increased from the previous 35 to 45 billion. The governor of the FED specified that liquidity injections in the US banking system will continue. This is not a resumption of Quantitative Easing, the governor specified. However, actually the Fed's run on liquidity does not seem any different from that of $\mathrm{ECB}$, which at its October meeting restarted the QE, with purchases of securities for $€ 20$ billion per month.
} 
distribution is exacerbated also by the tax evasion, which remains high in Italy and is partially responsible for the wealth accumulation within the privileged classes.

Really, the progressive exhaustion of the potentials in support policies is strongly troubling the survival of an economy management that essentially is focusing on the same old therapies to fight the declining cycle. But that focus is wrong because the economic cycle is not a bad thing: it's a necessary tool to bring the system back to price stability and constant growth; if this tool, however, is left to act. Now we are at the point that the exhaustion of all resources available to the old support policy, requires the need to find alternatives. But no alternatives are coming on. Ergo, it would seem that the time has come for a breakthrough.

I mean that a new lever of managers not stifled by the pallium of fiscal and monetary policies, finally would hear the voice of the economic system, which essentially claims for a sort of laissez-faire to natural tools: in order to bring the economy gradually back - though paying some tolls - to the condition of sustainability and linear growth.

In the meanwhile, we can wonder how will evolve in the coming years an economy like the Italian one, which suffered a severe recession during the 2008-2012 financial crisis and is still exposed to a very low inflation, below the European average. ${ }^{6}$ The double recession during the years 2008-2012 did not resolve the instability situation in the economy, as demonstrated by the marked tendency to deflation. In short, in the 2000s Italy shows a zero growth on average, while the decline in GDP suffered in the severe financial crisis of the first decade of 2000 wasn't recovered yet. (Roubini, 2011)

Therefore, the case of Italy could act as a precedent, in the sense that the financial crisis of the years 2008-2010 penalized more the economy of the "Bel Paese" compared to the other G8-countries, due to the greater financial fragility caused by the high public debt. The high debt didn't allow to dispose of resources for interventions to support the economy cycle throughout the financial crisis, at the level of those implemented by the USA, France, England and Spain. With the incongruous result that the public debt jumped to $135 \%$ in terms of GDP, due to the decline in the denominator. Given the excessive public debt, the presence of a creeping deflation brought also an inconsistent development, a sort of weakness linked to the mother crisis of 2008-2010. A long crisis during which a series of governments of different composition made various interventions but all with the mirage to solve the difficult situation with repetitive welfare policies, which finally further aggravated the public budget.

With inconsistent results, as it's irrefutably confirmed by the poverty progress in Italy during the previous ten years. The welfare mechanism could do nothing to correct the situation, because the persistence of an excessive public debt is an unstoppable engine that pushes income and wealth towards the higher social levels, while instead is depressing the living conditions of a large part of the community.

Apart from these considerations on the effectiveness of social interventions, one fact seems incontrovertible. The margins for action of fiscal policy in Italy are now dramatically reduced. On the other hand, the monetary policy is centrally managed by the ECB, and therefore outside the intervention area of political groups. The only chance we have is the debt reduction, which however does not find any defender champion within the political classes. Given this picture, how can we imagine the "Bel Paese" evolution in the coming years? To give some real and not magical answers, we should reflect on the long pause that blocked the country's development for twenty years.

Well, according to the sustainability theory, the economic conjuncture is a mechanism to reduce the instability of economic systems. This mechanism attenuates, through the recession, the anomalies produced by the exit from the stability path. Moreover, the chronic slowdown of the economy - which in Italy has lasted for over ten years - should be compared to a sort of continued mini-recession. A mini recession that acts as a sort of compression over the sinuous cycle, which therefore flattens until to stay paused. Therefore, if the conditions of public finance would remain balanced or even better in decrease due to the inconsistency of results in the long series of pro-cyclical interventions, then a positive turnaround in the Italian economy could finally take place.

\footnotetext{
${ }^{6}$ In October 2019 the harmonized annual inflation average (HICP) in Europe stood at $0.73 \%$, down from $1.4 \%$ at the beginning of the year. In Italy the progression is more evident: in October, HICP inflation was 0.19\%, down from 0.9\% at the beginning of the year.

${ }^{7}$ In 2017 in the European Union there were 112.9 million people at risk of poverty or social exclusion, equal to $22.5 \%$ of the European population. Compared to 2008 it's a decrease of 3.15 million people.
}

In Italy, instead, the situation is reversed: in 2008 the people at risk of poverty were 15 million, while in 2017 they were almost 17 and a half million, that is $28.9 \%$ of the population. Therefore, 2.3 million people are affected by the poverty increase. 
We certainly cannot interpret whether this change would actually take place and when. However, it seems that the conditions for a better adjustment may have already occurred. This positive perspective is linked, by the way, to the expectation that the public debt would be inserted in a path of gradual decline, in combination with the poor results achieved and the exhaustion of a real space for fiscal policy action.

Obviously, this hypothesis is closely linked to the evolution of global economy, and of the USA and China in particular. On this ground, however, the situation appears somehow different.

\subsection{The Unchecked Use of Fiscal Policy. The US Case}

The North American economy shows the merit of a good resilience after the severe financial crisis of 2008-2010. A positive value, certainly, which seems however to hide many uncertainties. First of all, the main symptom of instability is - let me repeat it - the low inflation. The recent meeting of the Federal Reserve recalls the stress resulted from the inflation tendency to lower, which is cited as the cause of the heavy and sharp fall in interest rates, within an economy travelling at 2.6\%, expected for 2019 and marking an unemployment rate at an all-time low.

An intriguing mix of a healthy economy and messengers that instead lead to an upcoming downturn for the economic cycle. On the other hand, the excesses of fiscal policy affect the financial system, which saw an unexpected rise in the overnight rate (up to $10 \%$ in September), due to an equally unexpected liquidity shortage on the interbank market (see: note 8). From mid-September to the end of November, the FED injected $\$ 250$ billion into the market, increasing its budget from $\$ 3700$ to almost $\$ 4000$ billion. Ironically, it has been said that the operation was a mini-QE.

Technical reasons are certainly not lacking for this sudden liquidity shortage inside the interbank market, not least the acceleration of public debt and the great quantity of new securities draining liquidity from the market. The financial crisis in the US interbank market has also been caused by problems of 'window dressing' of the European banks and a Japanese bank highly exposed in dollars and acting on the US repo market. But apart from the specific reasons, the fact remains of a market that continuously asks for new liquidity just to keep a distorted development of the economy.

Looking from a careful perspective at the two economies (USA and Italy), we must say that they had a different history throughout the 2000s. First of all, the great speculative bubble on Real Estate has had a global dimension, but the first impetus seems to have originated beyond the Atlantic and, finally, also the financial crisis of 2008-2010 has started from the United States. We should therefore consider that in the first decade of 2000 a long history of errors and oversights allowed the formation and then the collapse of the serious speculative bubble. (Reinhart, 2009)
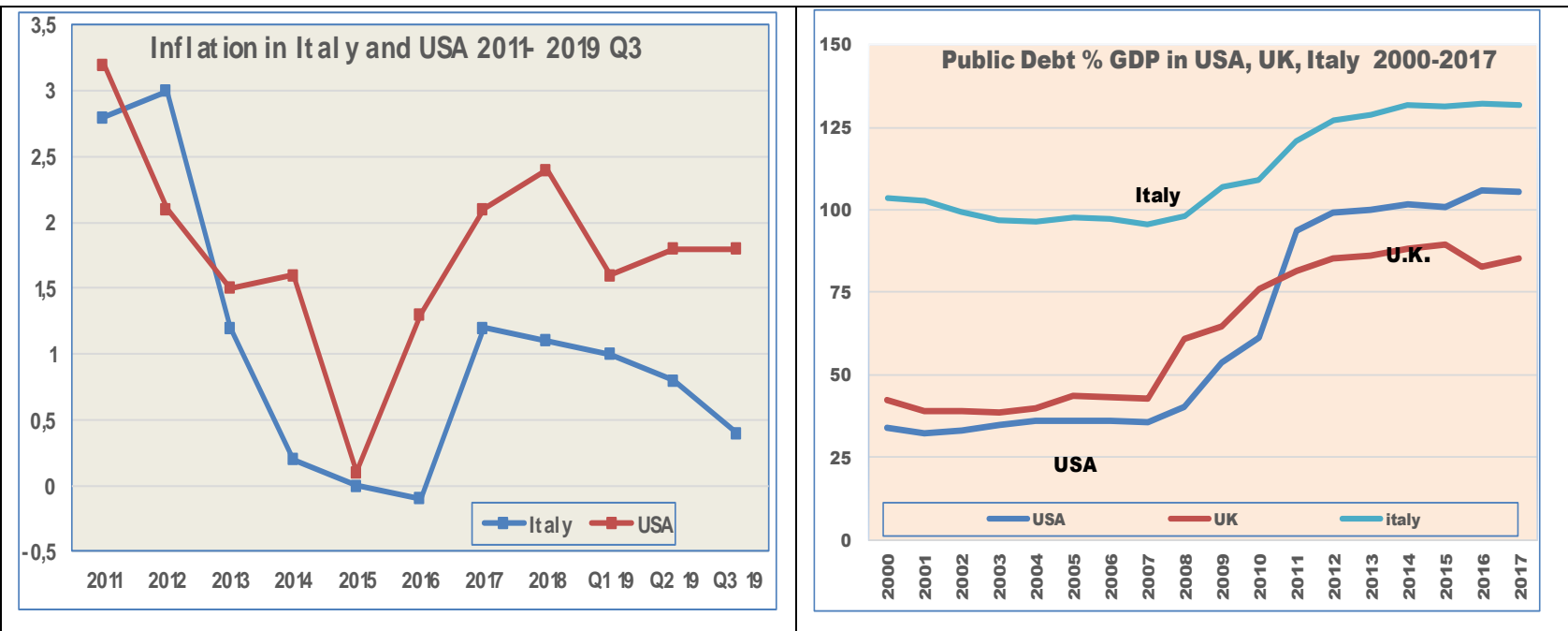

Figure 2. Inflation and Public Debt in USA and Italy

Source: Elaboration on OECD data

According to the economy of sustainability, the recession is the natural weapon used by the corrective system for the gradual return of the unstable system on the path of balance with nature. In the case of the USA, the shock of the 2000 financial crisis for its strength was comparable to that of '29. The dramatic involution of the last century was extended throughout the thirties and was overcome only during the World War I.

The severe economic turnaround of 2008-2010, is not comparable to that of the last century, because the correction of the unstable system has been partially blocked by the massive use of fiscal policies. Due to the strong fiscal pressure, 
within the few years from 2008 to 2012, the public debt grew by around 20 points in terms of GDP. As we can see from Figure 2, the public debt graph shows the surge of the debt curve. This was possible because the management of public finance during the late nineties was thrifty with the debt fallen below 50\% in terms of GDP. (Geithner, 2014)

All right then, but with a question. There is no doubt that, on the social plan and for the day-to-day economy, the control of the strong recession triggered by the financial crisis avoided a repetition of the drama experienced in the 1930s. However, good results can have also a dark side. First, on the social level the consequences can be dangerous, although partly balanced by the undoubted social advantage of the quite rapid recovery of economy and employment.

In the USA - as also in Italy - the unequal distribution of income and wealth has increased to the advantage of privileged categories, in conjunction with the increase recorded by public spending. ${ }^{8}$ These effects on the distribution of goods and resources deriving from the crisis and the post-crisis, could mean that the robust intervention of public spending reduces the potential damage of the financial crisis, but with a clear marked advantage for the very rich people. From the point of view of sustainability, the target of an important recession as that caused by the speculative bubble, is the excesses in the wealth and income distribution. As saying that its aim is to adjust the plan of altered social distribution; this consequence of the economic systems instability is measuring the distance of the economy from the path of sustainable growth.

On the other hand, the doubt remains about the dark side for the recession partial block. The slowdown should certainly mean that the rebalancing of the economic system entrusted to the economic turnaround - at least partially - could not have taken place. We must therefore assume that the natural correction has been postponed to a future event. Which, however, may not take place, precisely because of the offensive started by the renewed use of policies to fight the recession.

However, it should be considered that the major financial crises are starting a corrective process that can go further beyond the need to recover stability (Geithner, 2014). The collateral damage caused, because of the cyclical involution, are mainly affecting the banking system. With reflections, however, that can multiply the negative wave. The public intervention in favor of the major banks, badly hit by the unexpected strength of the recession, could therefore not be considered as a form of natural recession block. But rather just an appropriate choice, which therefore counteracts an excessive conjuncture narrowing, compared to the objectives to correct an unstable economy. It is therefore probable that an inactive behavior of the policies could be as risky as exceptionally large interventions, as in the case of the USA and also of some European countries.

In this regard, we should remind the attempts of monetary stabilization at the time of the crisis of the 1930s, which led most of the major economies of the time to link their currencies again to gold after the end of the Great War. The gold standard created in the early thirties a severe deflation that worsened the difficult economic situation and set the ground for a crisis continuation until the World War II. ${ }^{9}$ A collateral damage that multiplied the consequences of the crisis and extended its effects, certainly quite beyond the corrective action proposed by the serious speculative crisis, to bring the economy back on a more balanced development path. (Bernanke, 2000)

${ }^{8}$ The United States recorded a government debt equivalent to 106.10 percent of the country's Gross Domestic Product in 2018. Government Debt to GDP in the United States averaged 62.31 percent from 1940 until 2018, reaching an all time high of 118.90 percent in 1946 and a record low of 31.80 percent in 1981. Source: U.S. Bureau

9 The USA returned to the gold standard in 1919, and other European countries and Japan reinstated the gold parity a couple years later. Considering the limited gold supply of the early 1920s, the European countries and Japan decided on a partial gold standard, where reserves consisted of partly gold and partly other countries' currencies. This standard is known as the gold exchange standard. Because a metallic standard requires maintaining the external balance, the USA was trying hard to prevent fluctuations in its gold reserves. In fact, the dangerous direction at that time was to lose a substantial amount of gold reserves. To avoid losing gold reserves and promote incoming capital flows, the U.S. tried to keep interest rates higher through contractionary monetary policies.

Declines in the money supply led to deflationary pressures, which created considerable problems for the banking system. Similar to the British pound, the dollar experienced a speculative attack in 1931. Foreign and domestic investors and U.S. banks were converting paper money into gold, depleting the Fed's gold reserves.

Some economists blame the Fed's insistence on the gold standard for the long duration and the severity of the Great Depression. Holding on to the gold standard prevented the Fed from implementing expansionary monetary policies to stimulate the economy and act as a lender of last resort during the time of bank runs.

In 1934 , the gold parity implied an over 40 percent devaluation of the dollar, from $\$ 20.67$ to $\$ 35$ to the troy ounce (a measure that is used to weigh precious metals, 1 troy ounce $=31.1034768$ grams). Then, USA left the gold parity in 1934. Information received since the Federal Open Market Committee met in September 
Just to say that the forms of collateral damage occurring in large-scale financial crises can be of different nature, but all are an indirect consequence of the corrective recession. And they must therefore be fought through monetary and fiscal policies, as far as possible, without anyway affecting the natural correction factor manifested during the natural recession.

The virtuous fiscal policy of the 1990s in the USA made it possible to dispose of the public resources' reserve to counteract the intensity of the financial crisis, through massive fiscal policy interventions. The public finance balance at the beginning of the 2000s made possible an exceptional ability for intervention in the post-crisis, nevertheless it didn't represent a shield against the formation of a speculative process comparable to the '29. The reasons why the speculative process was loaded, cannot be defined. It could be argued that the long season of the fight against recession was the platform from where the speculative fire started.

As saying that if and when the tension imposed by the tendency to stability, innate in all economic systems, does not find a way out due to the contrast of monetary policies, there would be no other way than the speculation-crisis paradigm to bring the distorted economy back on the stability and sustainability path. Even as a result of a long period of (apparent) calm within the economy, a precarious and deceptive apathy can be widespread about the risks of an economy under speculation. A sort of mirage of an endless growth, which unfortunately turns into a bursting bubble, just like a mirage.

Now, just the fact that such an exceptional speculative event found space and exploded in the USA, suggests that the partial corrective effect of the recession during the first decade crisis, due to the obstacle of the support policies, may have a dark legacy. A legacy that will have to be paid sooner or later. If this is true, we should reflect on the sharp rise in public debt, which is the cause of the deflation tendency spreading also in the USA. The public debt, on the other hand, has suffered yet another stroke with the fiscal maneuver implemented in 2017 and in force since 2018.

The fiscal maneuver cuts taxes by $\$ 1500$ billion, increasing the debt load by the same amount, with a clear advantage for the privileged categories. A maneuver destined to increase the social malaise, due to an increasingly unequal wealth distribution. Malaise only partially mitigated by the unemployment dropped to its lowest rate.

The problem arising is the impact of this maneuver, which meanwhile had the effect of curbing the economic correction through a return of liquidity within the market, which accelerated consumption but not investment. Apart from the market sentiment that is looking with concern at a recession within the next 12 months, we should reject the thesis that a cyclical turnaround would be near in the USA, after a long calm of more than ten years from the 2008-2010 great financial crisis. A sort of regularity inside the economy cycle, with calculable recessive involutions, is absolutely impossible because the cycle is a disease of the system. A stable system does not suffer from the cycle sinuosity but grows linearly and with an inclination depending on the potentials. Moreover, due to the malaise, the conjuncture cycle tends to change with the decreased recoveries and the recurrent crises.

Well, the sentiment indulging towards a near recession could in effect confirm that the penalty to be paid for the correction interrupted during the financial crisis strongly may appear in the US market. In other words, the announced crisis could be nothing but the recession wake of ten years earlier, which didn't have the opportunity to be fully expressed with its corrective extent. However, this issue could also be complicated by the intervention of the fiscal maneuver implemented in 2018.

Apart from the partisan reasons that influenced the approach of fiscal maneuver, the fact remains that it can be configured as an improper follow-up of the great intervention made by the conjuncture support implemented during the years of the financial crisis. In other words, it could be seen as another attempt to postpone the negative legacy already accumulated over the past decade, due to the block imposed over the natural cycle.

Therefore, the recent fiscal intervention promoting private income to the detriment of public sector, could add and increase the pending negative legacy and, consequently, would accentuate the recession tendency of the US economic system. Also, because with a public debt that reached the threshold of $100 \%$ of GDP, we have to admit that there is no further real space for other fiscal maneuvers directed to confine the evolution of the economy cycle.

The attention of the markets thus moved over the monetary policy, which is essentially required to carry a supply function to the retreating fiscal policy. Nevertheless, even on this ground are not lacking some problematic aspects. During 2019 the FED decided to lower the target range for the federal funds rate, for the third time in the year, up to $-1 / 2$ to 1-3 / 4 percent. (see note 3 ) Therefore, with interventions in contrast with the still strong economic trend, thereby responding to the slow growth forecasts. The decision adopted in 2017, to initiate the slow reduction of assets in the Central bank's balance sheet (from 4300 in August 2018 to $\$ 3800$ billion in August 2019), was frozen. The Central Bank's "term repo" interventions restarted then from the autumn, to control the lack of liquidity in the interbank market. (see note 5) 


\subsection{Some Hypotheses on the Short-Term Prospects for the Global Economy}

The march of the global economy towards a corrective recession doesn't yet seem in sight. Much depends on the declinations of monetary policy during the coming months. In the meanwhile, seems to prevail a fading conjuncture on a global scale, according to a patchy model. Therefore, we could maybe dismiss the very problematic hypothesis that the call to recession would be synchronized, thus pushing a mutual intensification of the development downward trend.

The remaining problem is the missing economic turnaround for the two champions of the global economy, the USA and China. Well, in both cases we observe that is prevailing the logic of current governments who fear to lose consensus on the wake of declining economy. A logic not combining at all with an economy unstable and out of the stability path, unfortunately suffering from periodic alterations. Trying to bring the altered economic systems back to the stability path by putting walls against the natural evolution of the cycle, it is a mechanism without solutions. Because the corrective system irrevocably follows the stability law logic and, therefore, is seeking the way to restore the natural development in a reasonable time.

The long phase of stagnant economy that affected Italy for the last twenty years could be a kind of premonition about the global economy destiny. Along this path of development insignificance, are also moving Europe and above all Germany. The reasons inducing to a development pause can be insignificant, in the sense that they may be just pretexts but really are symptoms of malaise for the pressure exerted by the natural correction to realign the development cycle.

In this sense and according to this line of thought, it doesn't seem a mere study hypothesis but an actual potential eventuality the possibility that the whole global economy in the coming years would curb according to this perspective; that is a progressive and serious slowdown in the growth pace, going towards a sort of corrective pause investing all the continents. Now, if we assume that the economy's run is subjected to the natural balance for the stability pressure tendency of economic systems, we must also admit that all efforts to control the corrective recession can only postpone the solution of the problem. But obviously they are unsuitable to restore the natural order.

Ergo, we can just hope that the pause pattern apparently prevailing on a general level could essentially represent a way out from instability, although with the penalty of social and economic uncertainty. Facing this hypothesis, only relatively neutral, means that the economic trend in the two major economic countries should also tend towards a relative pause during the coming years.

In other words, the US economy, which is already moving towards a cooling cycle in the year of the presidential elections, should show a growth decline in the next two years that would average around $1 \%$ per year. A hypothesis envisaged by the CBO, ${ }^{10}$ noting that the development over the potentials in the two-year period 2018-2019 could be followed by a period of low growth below the potentials, thus balancing the accelerating effect produced by the tax returns in the three-year period 2018-2020.

A similar downward trend can be observed in the Chinese economy trend. For the next year, a more decisive drop in its accelerated development is expected, which would stand therefore at one or two points below the average of latest years. Therefore, the expected official figure of $5 \%$ for 2020 , would have a significant contraction. Thence, the official figure could be optimistic, so in the current year the GDP could increase by no more than $4 \%$.

In China also, the logic of growth at all costs is obtained through a difficult fiscal policy in favor of public and private enterprises. On the same wave, the monetary policy has flooded the markets with new liquidity, thus carrying out an action to support the economic cycle, no less effective than the actions of main Central Banks.

As saying that the main world economic regions, although divided by a different vision of the democratic life, are in the same way subject to the need to show the effectiveness of the implemented policies to the communities of their territories. In the assumption that good economic results essentially mean a widespread consensus across the communities. Now there is no doubt that in China the country's great march towards an accelerated modernization has essentially stabilized the centralist regime.

${ }^{10}$ Output. Real GDP is projected to grow by 2.3 percent in 2019 and by an average of 1.7 percent per year from 2020 through 2023. Most of the growth of output in CBO's forecast over the next few years is driven by consumer spending and, to a lesser extent, business and residential investment and exports. Compared with the robust pace of output growth in 2018 - 3.1 percent, the fastest annual growth since 2005 - output growth is projected to slow in 2019. That projected slowdown largely results from an anticipated slowdown in the growth of business fixed investment, as the positive effects of recent tax legislation on investment growth begin to wane, and from a sharp reduction in federal purchases starting in the fourth quarter of 2019 that would occur under current law. CBO - The Budget and Economic Outlook: 2019 to 2023 - January 2019 
In China, as in general for the global economy, the era of growth spurt is now passing and we can expect some less prosperous times, if not a real pause. Apart from the consequences on a more political level, it's clear that even in China the ultra-accommodative monetary policy and the supporting fiscal policy cannot go on with no end. Therefore, the exclusion of policies to support the economy is destined to have an important impact on the scenario of the coming years. As saying that there isn't a great difference in behavior between the different areas of the world regarding the economy management and the concern about the economic cycle stability.

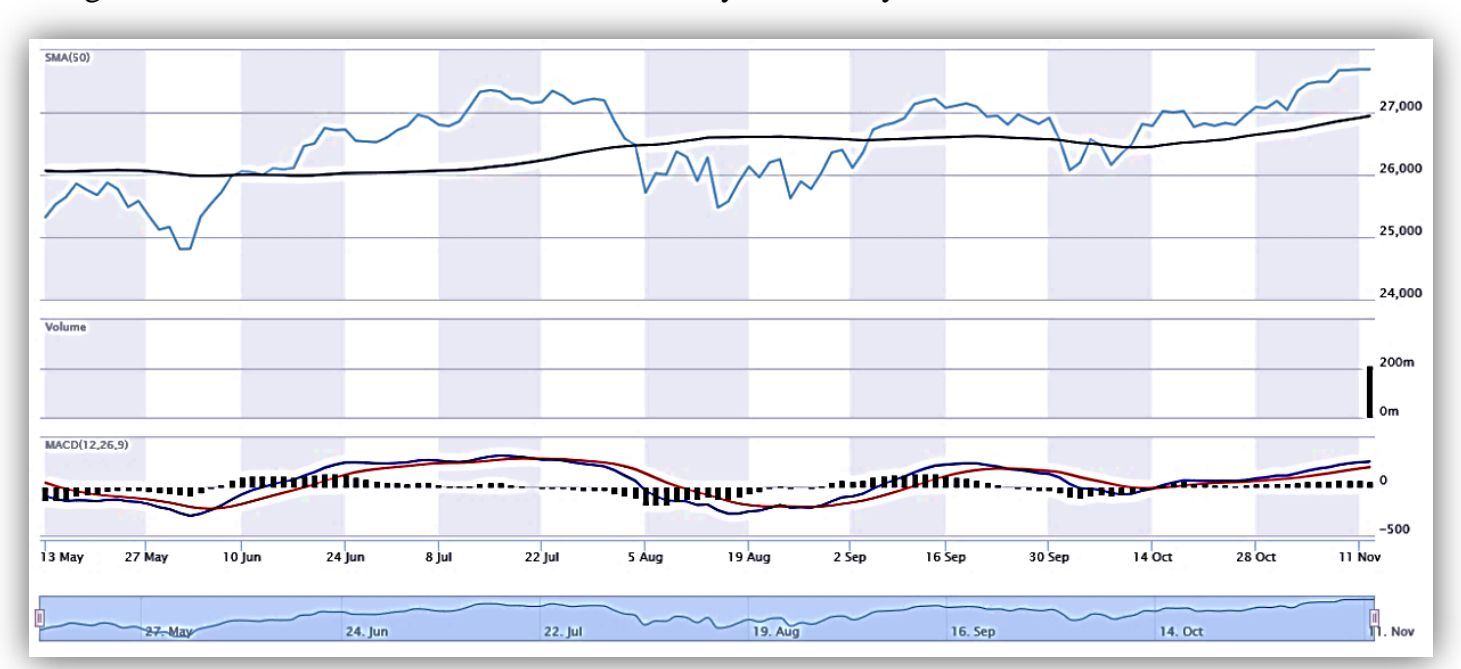

Figure 3. Dow Jones Industrial Average from May 2019 to November 2019 (27681)

Source: Market Watch, financial information website

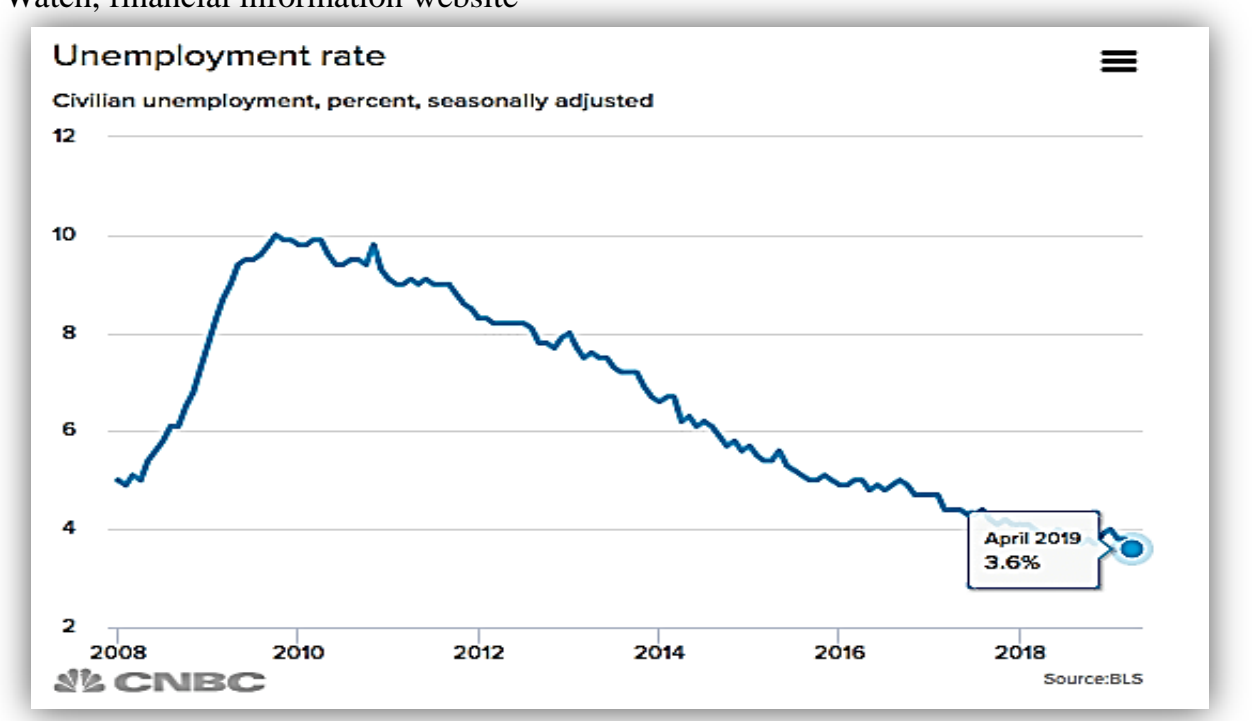

Figure 4. Unemployment rate in USA - 2008-2019

Well, it's not unlikely that this behavior could continue in the coming years, albeit with the use, resized over time, of some technical tools. Therefore, there could be a tendency towards a progressive efficiency contraction of economic systems and a substantial pause for the main economies. A landscape certainly unsatisfactory, but not very disturbing yet.

However, a signal coming from across the Atlantic should not be overlooked. In particular, the alternating tensions that troubled the US economy and the main stock markets. As can be seen in Figure 3, for the main US market the Dow Jones showed a very variable trend, touching historical highs and then falling by a few hundred points and so on again for new highs and following falls. This circular trend is the market response to the US administration and White House decisions to control the trade deficit, interfering in international relations with the imposition of duties that affected Europe but above all China.

Without going into the substance of this extremely difficult issue, the protectionist vision of the US presidency has deeply interfered with the economic situation, as demonstrated by the drops of the Dow Jones curve in correspondence 
of the imposition of duties in a crescendo of mercantile nature. In correspondence of the reverse of the US Stock Exchanges (followed worldwide by the main Stock Exchanges), the United States and the main global economies recorded a pace decline, even no marked.

An obvious consequence of the effects on the real economy of the involved countries, and in general of international trade, due to the negative pressure exerted by the new structure of the international trade, which is now taking shape. But all that is also caused by the negative reaction of operators and families in the new scenario, that brings probably also a progressive decline in trade relations and therefore in the potential growth of world economy.

In this regard, we should note the tension pervading the US stock exchanges and in particular the Dow Jones which, after each decline, resumes its share and reaches new historical highs at the end of 2019 (about 27,000 compared to 13800 at the end of 2007, before the burst of speculative bubble). This tension towards growing quotations, despite the further tensions impressed by the US protectionist policy, doesn't have any objective base related to the growing real economy that is instead in a reflection phase and is probably declining. This unexpected behavior adds to the already observed theme of the long run of the economy and the acceleration it has undergone since 2018 for the tax cut.

Certainly, this anomalous behavior seems to demonstrate that from 2018, that is with the entry into force of the tax reform strongly desired by the US presidency in favor of high incomes mostly, the boost given to the economy may have taken an almost speculative nature. The unemployment decline at historical level does not counteract this view. We have to note that in the years of the great boom formation in the 2000 first decade, the unemployment was already reduced (Figure 4) and was traveling towards a record low (4.9\% in 2008).

Paradoxically, the protectionist initiatives of the US presidency, which in subsequent waves affected the two-year period 2018-2019 and caused worried market reactions in the USA and worldwide, had the unexpected effect on the economy trend to curb or mitigate the speculative pressure. As saying that the exuberant initiatives in terms of international relations adopted by the US presidency may have had the effect of slowing down the speculative pressure put in place by the administration itself to give strength to the conjuncture.

Well, it can be assumed that the continuation of the protectionist policy may have the consequence of mitigating - or perhaps even dilute - the excessive pressure that was accumulating, due to the improper decision to feed the economy growth through the fiscal measure of tax cut. If this would be proven in the coming months, the expected economic turnaround in the USA should be significant already during 2020 to then consolidate in 2021.

\section{Conclusion}

The sustainability issue is not a recently invented fashion when the climate change has attracted the attention of the wide public. It's instead a synthetic expression to give a shape to the tendential balance in nature, which is inspired and supported by the stability law of economic systems. Not a simple fashion then, but a decisive factor to allow the long presence of life and humankind on the planet.

According to the sustainability perspective, the desire to interpret the events interesting the global economy and the large continental groups means trying to understand the anomalies and the signs of those alterations occurring, due to the abandonment of the linear and constant path of balance and growth. In the assumption that humanity, having survived immense difficulties, natural perturbations and endless conflicts, owes its survival and its life perspective to the irrevocable balance between the life development and the planet preservation. According to a natural order intended to safeguard resources for the future generations.

The problem calling into question the sustainability theory concerns the tools used to try to dominate and control the anomaly of the conjuncture cycle. Now, the economy cycle is the symptom of a disease contracted by the economy. And more than only a symptom of malaise, it's also the medicine to fight on a natural level the deviation from the stability path. By letting work the corrective tool, we should presume that the economy is gradually moving towards the natural balance.

Therefore, the problem concerns now the use of the tools provided by fiscal policy and then by monetary policy to restore the economic conjuncture, pushing it to move along a stability and linear growth path. In other words, the interventions of fiscal and monetary policies are called into question to accelerate the return of economic systems to stability, alternatively but quite often even in opposition to the corrective natural motion.

Experience seems to show that the weak point is precisely the substantial failure of the economic cycle support strategies to remove or at least mitigate the systems' instability. In other words, the results obtained in the economic field with these maneuvers are unable to solve the problem. A crucial question that is explained by the global tendency of economic systems to deflation. The trend towards deflation is mitigated by the use of extreme monetary policy resources. However, both the falling prices and above all the growth line, which is becoming more and more creeping, 
remain substantially untouched. Both phenomena in fact, prices and growth, may accentuate when the fiscal policy interventions are exhausted.

This is a critical issue that calls into question the value of interventions considered "quod melior" in the classical approach. There is no doubt that in the short and medium term, the relief initiatives for declining growth have given some appreciable results. However, the point remains that the context, while reacting to the pressures exerted by fiscal and particularly monetary policies, fails to erase the instability mark that is certified by the latent deflation, which is extended throughout the world economy.

The contrast between the adjustment policies of economic cycle and the natural corrective mechanism, which is expressed by the same conjuncture cycle, appears to lie in the substantial clash between the natural and the classical schemes of economy. The natural tendency chooses the relatively sustainable recession form, which can be controlled precisely through the fiscal policies, when these do not play a role of opposition to the natural maneuver but are aimed instead to alleviate the social effects possibly caused.

In other words, fiscal policies aimed at counteracting the normal deployment of the recession are essentially moving in opposition to the natural process aimed at overcoming the instability state and the deviation from a sustainability condition. The effects, while improving the status quo, are just temporary and can only delay the correction process over time. Meanwhile, the fiscal policy measures aimed at mitigating the damage caused by the recession to the disadvantaged parts of the community, do not make any negative pressure on the natural correction process. Although they reduce the economic and social damage caused by the economic reversal.

\section{References}

Bernanke, B. S. (2000). Essays on the Great Depression. Princeton University Press - Princeton, New Jersey.

Congressional Budget Office USA - The Budget Outlook for 2018 to 2028.

Cossiga, G. A. (2017). Stability and Instability of an Economic System: Considerations. Review of European Studies, 9(3). https://doi.org/10.5539/res.v9n3p8

Cossiga, G. A. (2018). Signals from the World of Economics. The Price Constant and the Democratic Issue. International Journal of Social and Administrative Sciences, 3(1), 1-21. Retrieved from www.aessweb.com/pdf-files/IJSAS-2018-3(1)-1-21.pdf

Cossiga, G. A. (2018). The Search for Inflation on a Constant Basis at 2\%. International Journal of Science, Social Sciences. https://doi.org/10.11648/j.ss.20180704.13

Cossiga, G. A. (2019). The Economy of Sustainability: Some Consequences on the Economic Theory. Theoretical Economics Letters, 9(8). https://doi.org/10.4236/tel.2019.98187

European Central Bank - Press Conference. Mario Draghi, President of the ECB of the EC. Riga, 14 June 2018. Retrieved from https://www.ecb.europa.eu/press/pressconf/2018/html/ecb.is180614.en.html

Geithner, T. F. (2014). STRESS TEST: Reflections on Financial Crises. Published May 12th, 2014 by Crown Publishing Group (NY).

IMF -International Financial Statistics - Database, various years.

IMF -World Economic Outlook Update, July 2018.

Krugman, P. R. (2009). The return of depression economics and the crisis 2008. W.W. Norton \& Company, Inc. New York.

Lindberg, L. N., Maier, S., \& Barry, B. (1985). The Politics of Inflation and Economic Stagnation. Brookings Institution Washington D.C.

OECD - OECD Stat Database, various years.

Reinhart, C., \& Rogoff, K. S. (2009). The Time Is Different - Eight Centuries of Financial Folly. Princeton University Press -Princeton and Oxford. https://doi.org/10.2307/j.ctvcm4gqx

Roubini, N., \& Mihm, S. (2011). Crisis Economics: A crash Course in the Future of Finance. Penguin Books.

\section{Copyrights}

Copyright for this article is retained by the author(s), with first publication rights granted to the journal.

This is an open-access article distributed under the terms and conditions of the Creative Commons Attribution license which permits unrestricted use, distribution, and reproduction in any medium, provided the original work is properly cited. 